\title{
Familia, prácticas empresarias y poder político. Un estudio comparado de los casos de Felipe y Manuel Posse en el contexto agroindustrial azucarero tucumano, 1830-1890
}

\author{
por Francisco Bolsi
}

Abstract. - Since the earliest activities of the Argentinean sugar industry, historians have debated its development. The focus of the controversy was on the need or desirability of State protection and encouragement of the regionally located industries. A case study on members of one of the major sugar producing dynasties, the Posse clan, helps to broaden the understanding of economic trends in the sugar factories: from the time of its creation through decision-making for investments, modernization of the machinery, the reactions of the family environment prior to the closure of factories, and the links between this process and the political position of the Posse therein.

\section{Introducción}

El siglo XIX fue clave en los procesos formativos y de fortalecimiento de las burguesías regionales en América Latina, hecho que coincidió con la inserción progresiva del liberalismo económico, el desarrollo de sectores agroindustriales y la organización de los Estados Nación. ${ }^{1}$

En la Argentina, la instauración del Orden Conservador propicio la implementación de un sistema agroexportador primario - carnes y cereales

1 Al respecto de la producción historiográfica acerca de las burguesías latinoamericanas véase Heraclio Bonilla, Guano y burguesía en el Perú. El contraste de la experiencia peruana con las economías de exportación de Ecuador y Bolivia (Quito 1974); Mario Cerrutti, Burguesía y capitalismo en Monterrey, 1850-1900 (México 1983); Mario Cerutti/ Menno Vellinga (eds.), Burguesía e industria en América Latina y Europa Meridional (Madrid 1989); Guy Palmade, La época de la burguesía (Madrid 1998); Sergio Villalobos, Origen y ascenso de la burguesía en Chile (Santiago de Chile 2006). 
principalmente - hecho que favoreció ampliamente a la elite del litoral pampeano. ${ }^{2}$ Esta situación generó la implementación de estrategias de desarrollo económico con la finalidad de integrar al resto de las elites regionales al mercado nacional. ${ }^{3}$ En el noroeste, la elite tucumana con el apoyo del Estado Nacional reconvirtió la producción azucarera en un complejo agroindustrial destinado a satisfacer el mercado interno y transformarse en el eje del crecimiento económico de la elite.

La reconversión de la agroindustria azucarera sirvió como excusa para indagar desde una perspectiva comparada, las estrategias empresarias y el poder político de Felipe y Manuel Posse (tío y sobrino) - propietarios de los ingenios San Felipe y San Vicente - y determinar las causas que originaron el cierre de sus fábricas azucarera en la década de 1880.

Si bien esta temática fue tratada por la historiografía local, la originalidad de esta propuesta residió en tres cuestiones. ${ }^{4}$ En primer lugar se complementó el análisis de las trayectorias económicas con los aportes conceptuales de la historia de familia con la finalidad de comprender las estrategias familiares en este contexto. ${ }^{5}$ En segundo lugar se recurrió al bagaje historiográfico referidos a las familias empresas, subdisciplina de la historia de empresas, debido a que los actores en estudio se transformaron

2 Natalio Botana, El orden conservador. La politica argentina entre 1880 y 1916 (Buenos Aires 1998); Mario Rapoport, Historia económica, política y social de la Argentina (1880-2003) (Buenos Aires 2007).

3 Para el caso tucumano, las investigaciones de Marcos Giménez Zapiola, Jorge Bálan y Donna Guy se transformaron en trabajos pioneros al comprender la integración de las elites regionales como un proceso de negociación permanente entre los interes provinciales y nacionales. Véase: Marcos Giménez Zapiola (ed.), El régimen oligárquico. Materiales para el estudio de la realidad Argentina (Buenos Aires 1975); Jorge Balán, "Una cuestión regional en la Argentina: Burguesías provinciales y mercado nacional en el desarrollo agroexportador": Desarrollo Económico 18:69 (Buenos Aires 1978); Donna Guy, La política azucarera argentina: Tucumán y la generación del ochenta (Tucumán 1981).

${ }_{4}$ El trabajo de Campi y Bravo resulta una sintesis sustancial del tema azucarero en Argentina: Daniel Campi/María Celia Bravo, "La agroindustria azucarera argentina. Resumen historiográfico y fuentes”: Boletín de Fuentes. América Latina en la historia económica 11 (México 1999), pp. 73-93.

5 La historia de familia es una corriente historiográfica que lleva en los ámbitos académicos más de medio siglo. Para el caso europeo los trabajos de Laslett y Fladrin son de ineludible referencia: Peter Laslett, Household and Family in the Past Time (Londres 1972); Jean Flandrin, Familles: Paranté, maison, sexualité dans l'ancienne societé (París 1976). En el caso de la producción historiográfica argentina véase: Beatriz Bragoni, Los hijos de la revolución. Familia, negocios y poder en Mendoza en el siglo XIX (Buenos Aires 1994); María Bjerg/Roxana Boixádos (eds.), La familia. Campo de investigación interdisciplinario. Teorías, métodos y fuentes (Quilmes 2004); José Luis Moreno, Historia de la familia en el Río de la Plata (Buenos Aires 2004), pp. 35-60; Mónica Ghirardi, Matrimonios y familia en Córdoba. Prácticas y representaciones, 1700-1850 (Córdoba 2008). 
en empresarios azucareros del medio local. ${ }^{6}$ En tercer lugar, se utilizó la perspectiva comparada, como metodología de estudio, propuesta que enriqueció la propuesta de análisis.

Asimismo, Felipe y Manuel Posse integraban una familia prestigiosa del ámbito local, vinculada con la actividad azucarera desde su inicio. Sus integrantes detentaron el poder político local en la década de 1860 al ser elegidos como gobernadores, diputados y senadores provinciales y nacionales. El manejo exclusivo de la política generó rechazo por parte de la elite tucumana, quien no promovió ninguna otra candidatura de esta familia en el ámbito local hasta fines del siglo XIX. En cuanto al negocio azucarero, este clan familiar era propietario de seis ingenios a principios de 1870 pero a finales de este siglo sólo continuaban en actividad, el San Juan y la Esperanza.

A partir del contexto reseñado, cabe preguntarse lo siguiente: ¿La industria azucarera se transformó en una actividad económica central en los casos de Felipe y Manuel Posse o en caso contrario, sería posible identificar en un conjunto más amplio de actividades el porcentaje que esta producción representó? En todo caso, ¿el clan familiar experimentó una desarticulación en las relaciones intrafamiliares que podría interpretarse en una falta de interés por evitar el cierre de los ingenios San Felipe y San Vicente o desde un principio cada uno de los integrantes de este clan administró su fábrica de manera individual sin recurrir a la colaboración de sus parientes más cercanos? En todo caso, si la familia no tuvo ninguna responsabilidad en lo sucedido, ¿sería posible establecer alguna conexión entre el cierre de los ingenios azucareros con la situación política de los Posse a fines del siglo XIX o el cierre de estas fábricas no tiene vinculación con lo anteriormente planteado y fue producto de un contexto sumamente competitivo - cuya característica fue el éxito individual por sobre los colectivos - al que los Posse no lograron adaptarse?

Este trabajo se estructuró a partir del análisis de diversas fuentes. Se relevó la Sección Protocolos con la finalidad de indagar en la compraventa de inmuebles (tanto de la campaña como en la ciudad), las sesiones de poderes especiales y algunos testamentos de los actores sociales objeto de estudio. Se analizó la Sección Judicial Civil con el propósito de estudiar las sucesiones testamentarias y los conflictos en el entorno familiar. Se indagó

${ }^{6}$ Esta línea historiográfica se originó en los Estados Unidos, a mediados de la década de 1920, en el ámbito de la Graduate School of Business Administration de la Universidad de Harvard, al crearse en 1925 la Business Historical Society para la preservación de los archivos empresariales. Para el caso argentino véase: Marta Inés Barbero (ed.), Historia de empresas: aproximaciones y problemas en debate (Buenos Aires 1998); Santiago López/Jesús Valdivieso Gago, Historia económica de la empresa (Barcelona 2007); María Inés Barbero/Raúl Jacob, La nueva historia de empresas en España y América Latina (Buenos Aires 2008). 
la Sección Administrativa de Hacienda y la Compilación Ordenada de Leyes y Decretos de la Legislatura Provincial que contiene información referida a la política azucarera implementada por los gobiernos de turno. Se relevó la Sección Mayores y Menores de Contaduría que permitió un seguimiento de las actividades económicas de los Posse y el diario El Orden con la finalidad de analizar las causas que ocasionaron el cierre de los ingenios azucareros.

\section{Actividades económicas, políticas y reproducción social. La situación de Manuel y Felipe Posse en la primera mitad del siglo XIX}

Felipe era el hijo menor de Manuel Posse ${ }^{7}$. Desde joven se interesó en las actividades comerciales pero carecía del capital suficiente para instalar un negocio en la ciudad. Por este motivo, su padre le adelanto $\$ 5000$ en concepto de legítima herencia para instalar una pulpería en la ciudad. ${ }^{8}$

Este clan familiar, en la primera mitad del siglo XIX, se identificó con el unitarismo y conspiró contra el gobernador Federal Alejandro Heredia. En 1834, Felipe organizó con algunos comandantes de milicia un levantamiento en contra de Heredia que fue descubierto y desarticulado. Esto le costó el exilio de la provincia, regresando recién 1849 según consta en la documentación del AHT. ${ }^{9} \mathrm{Al}$ establecerse de nuevo en Tucumán se dedicó a las actividades comerciales y a la compraventa de propiedades..$^{10}$ Felipe se casó con su sobrina carnal, Rafaela Posse Insúa, hija legítima de Simón Posse y María Josefa Insúa ${ }^{11}$.

${ }^{7}$ Manuel Posse y Blanco, nació en el villa de Camariñas (la Coruña), el 07/10/1753. Hijo de don Domingo Antonio Posse y de Doña María Blanco y Martínez. En: Archivo Parroquial de Camariñas, libro de bautismos $n^{\circ} 1$, f. 119. Se destacó en el contexto tucumano por el volumen de sus transacciones en las primeras décadas del siglo XIX, hecho que le permitió acumular un cuantioso patrimonio. Felipe fue bautizado el 30/04/1806. En: Catedral de Tucumán, Bautismos, IX.

${ }^{8}$ AHT, Sección Protocolos, Serie A, año 1839, f. 21 a 24 (v).

${ }^{9}$ Felipe Posse pagó 12 pesos en concepto de impuesto por derecho de importación de frutos y 15 pesos por la patente de su tienda. AHT, Sección Administrativa, Manuales de Contaduría, 1849-1853, f. 54 y 56.

${ }^{10}$ En 1849 Felipe pagó 12 pesos en concepto de impuestos por dos carretas cargadas que provenían de Santiago del Estero. AHT, Sección Administrativa, septiembre 21 de 1849, Vol. 13.

${ }^{11}$ El casamiento de Felipe con su sobrina formó parte de una estrategia para resguardar el patrimonio familiar, pero también a consecuencia de compartir los mismos ámbitos de sociabilidad, hecho que despertó sentimientos afectivos mutuos. Esta práctica intrafamiliar fue recurrente en las siguientes generaciones. En: Jorge Corominas/José María Posse, Genealogía de los Posse, Inédita. 
Manuel Posse, era hijo de Vicente Posse - comerciante del medio local - y nieto del iniciador del clan familiar. Se dedicó al igual que su padre a las transacciones comerciales en Tucumán importando efectos de ultramar desde el puerto de Buenos Aires. Se comprometió con el unitarismo y participó en la Liga del Norte - movimiento insurreccional en contra del rosismo -, en 1840. Luego de derrotado este levantamiento, enfrentó persecuciones políticas y se le impusieron una serie de contribuciones forzosas. ${ }^{12}$ En 1844 contrajo matrimonio con Lucinda Silva Zavaleta - hija del ex gobernador don José Silva y de Tomasa Zavaleta Ruiz de Huidobro. ${ }^{13}$ Este enlace lo unió con una de las familias más prestigiosas de Tucumán, relacionada con las actividades comerciales y políticas.

En ambos casos, se identificó conductas económicas y políticas similares. En lo que respecta a la reproducción social, la diferencia sustancial radicó en las prácticas matrimoniales implementadas. Manuel relacionó a la familia Posse con otro prestigioso clan familiar del medio local como los Zavaleta mientras que el casamiento de Felipe implementó una estrategia matrimonial tendiente a proteger el patrimonio y reafirmar los vínculos intrafamiliares.

\section{El surgimiento de los ingenios San Felipe y San Vicente en Tucumán. Prácticas empresarias, estrategias económicas e inversiones entre 1860 y 1880}

La historiografía azucarera tucumana analizó el proceso de acumulación de capitales que permitió la modernización del parque industrial a comienzos de la década de 1880. Las interpretaciones de Giménez Zapiola, Jorge Balán y posteriormente de Daniel Campi, coinciden en que los recursos para la modernización procedieron de la creciente actividad manufacturera de la elite tucumana entre 1830 y $1870 .{ }^{14}$ Este proceso de acumulación fue acompañado por otras variables relacionadas con las vinculaciones políticas de la elite tucumana, el acceso al crédito y el parentesco sin las cuales no se entendería la reducción del número de ingenios y el monopolio de la producción en un pequeño grupo de familias de la elite en la década de 1880 .

12 AHT, Sección Administrativa, 1842, f. 234.

13 Jorge Corominas/José María Posse, Genealogía de los Posse, Inédita.

${ }^{14}$ Balán, "Una cuestion" (nota 3); Daniel Campi, "Espacio mercantil, unidades de producción y actores en los orígenes de la agroindustria del azúcar en Tucumán, Argentina, 1830-1870": Alberto Vieira (ed.), História do açúcar. Rotas e mercados (Madeira 2002), pp. 335-364. 
Las transacciones comerciales efectuadas por la elite tucumana en la primera mitad del siglo XIX generaron un proceso de acumulación de capitales que incidió a partir de 1850 , en una reorientación paulatina hacia la actividad agroindustrial azucarera. De acuerdo a Fandos y Murga esta conducta se asemeja a la que siguieron algunos sectores comerciales de América Latina en el siglo XVIII que presenta la consolidación de un núcleo burgués a partir de un sector mercantil. La gestación de dicho grupo, unida a una creciente mercantilización de productos, fuerza de trabajo y tierra es parte de un proceso de cambio más amplio, puesto que, "para algunas regiones latinoamericanas, el siglo XIX puede definirse como el período en el que se configuraron las formas capitalistas de producción"15. A partir de estos conceptos, se compredió que la adquisición de propiedades integró el proceso de diversificación de inversiones de la elite. ${ }^{16}$

Las actividades económicas de Felipe Posse comenzaron en 1855, año en el que adquirió una propiedad por un valor de 9.000 pesos bolivianos en la ciudad. ${ }^{17}$ Esta transacción marcó el comienzo de la compra de propiedades inmuebles en la capital tucumana a partir de la década de 1860, que fueron destinados a cuartos de alquiler, actividad rentable debido al aumento de la demanda habitacional por el crecimiento demográfico de la ciudad. ${ }^{18}$

Posse integró dos sociedades en el ámbito local. La primera de ellas con su primo Roque Pondal - Posse Pondal y Cía. - constituida en 1862 pero con presencia efectiva en las operaciones inmobiliarias recién en 1868. Ese año esta compañía adquirió dos propiedades en la ciudad por un monto de $\$ 2800 .{ }^{19}$ A partir de esta compra el vínculo societario con Pondal se disolvió transformándose Posse, en el único propietario de las mismas. En la segunda sociedad que constituyó - Felipe Posse y Cía. - incorporó a su hijo primogénito, Felipe Segundo. Esta empresa familiar comenzó sus transacciones inmobiliarias en 1867, año de su fundación. Sin embargo, en esta década su accionar en el medio local no fue significativo debido a que sólo se adquirió en la ciudad una propiedad por $\$ 500 .{ }^{20}$

${ }^{15}$ Cecilia Fandos/Patricia Fernández Murga, "Sector comercial e inversión inmobiliaria en Tucumán, 1800-1850": Travesía, Revista de Historia Económica y Social, Vol. II, N 5/6 (Tucumán 2001), pp. 181-232.

${ }^{16}$ Ibidem, p. 196.

${ }_{17}$ AHT, Sección Protocolos, Serie A, 1855, f. 96 (v).

${ }^{18}$ AHT, Sección Protocolos, Serie A, 1864, f. 356; 1865, f. 50, f. 197; 1866, f. 9 (v), f. 228, f. 231; Serie B, 1865, f. 92 (v); Serie D, 1868, f. 71; 1869, f. 105 (v); 1870, f. 227, f. 288.

${ }_{19}$ AHT, Sección Protocolos, Serie C, 1868, f. 63 (v), 64 (v).

${ }^{20}$ AHT, Sección Protocolos, Serie A, 1867, f. 207 (v). 
En la campaña se adquirió tierras por medio de vínculos societarios. En 1862, Felipe Posse compró con su primo Roque Pondal, propiedades en la zona de los Aguirre por un valor de $\$ 2175 .{ }^{21}$ En este lugar, se plantó surcos de caña y se emplazó un trapiche de madera en 1865 para fabricar azúcar artesanalmente. ${ }^{22} \mathrm{Al}$ culminar el vínculo societario con Pondal, las propiedades fueron usufructuadas por Posse, quien fue el único propietario.

En el transcurso de esta década Felipe adquirió nuevas tierras en los Aguirre extendiendo la superficie cultivada del ingenio. Estas transacciones se realizaron en nombre de Felipe Posse y Cía., vínculo societario constituido en el año $1867 .^{23}$

La constitución de diversas sociedades en la campaña por parte de Felipe Posse respondió a la necesidad de rentabilizar el negocio azucarero. La conformación de una empresa familiar en la que participó su primogénito fue la opción más coherente para Posse. De esta manera, deslindó responsabilidades concernientes al ingenio azucarero en Felipe (hijo), estrategia que le posibilitó otras operaciones económicas.

En el mismo período, Manuel Posse no adquirió propiedades. Sin embargo, no se mantuvo en el ostracismo económico debido a que se dedicó a las transacciones comerciales al igual que el resto de su familia. ${ }^{24} \mathrm{La}$ única noticia al respecto de Manuel data de 1864, momento en que constituyó una sociedad con su hermano Wenceslao Posse con el propósito de instalar una fábrica añilera en la zona de los Aguirre. El proyecto fracasó disolviéndose este vínculo societario. ${ }^{25}$ Este fue el primer intento de Manuel Posse por diversificar sus actividades económicas.

\section{La década de 1870}

En esta década la situación fue diferente. Felipe Posse incrementó la adquisición de propiedades en los Aguirre - lugar en donde funcionaba el San

${ }^{21}$ AHT, Sección Protocolos, Serie B, 1862, f. 42; Serie A, 1868, f. 167 (v); Serie D, 1868, f. 120.

${ }^{22}$ Con medios artesanales se define al proceso de fabricación del azúcar sin recurrir a la utilización de maquinaria moderna.

${ }^{23}$ Esta compañía invirtió \$ 2972 en la compra de estas propiedades. AHT, Sección Protocolos, Serie D, 1869, f. 26, f. 105 (v), f. 108; 1870, f. 23, f. 51 (v), f. 70, f. 135 (v), f. 154, f.172 (v), f. 185.

${ }^{24}$ En 1863 Manuel pagó \$ 10 en concepto de patente por su almacén de $3^{\mathrm{a}}$ clase. AHT, Manuales de Contaduría, Sección Administrativa de Hacienda, Vol. 18, 1863.

${ }^{25}$ Carlos Páez de la Torre, "Un industrial azucarero. Wenceslao Posse": Carlos Ferrari/ Ezequiel Gallo (eds.), La argentina del ochenta al centenario (Buenos Aires 1980), pp. 416436, aquí: p. 427. 
Felipe -, invirtiendo la suma de $\$ 4191 .{ }^{26}$ Esto se vinculó con el crecimiento del ingenio que paulatinamente se transformó en el eje de las actividades desarrolladas por Posse. Estas operaciones fueron efectuadas por Felipe sin la intervención de la empresa familiar, que disminuyó el volumen de sus transacciones en esta década. La compra de propiedades en la ciudad continuó siendo un eje económico significativo. En este período Posse invirtió \$ 1874 en operaciones inmobiliarias en la ciudad. ${ }^{27}$

El año 1877 marcó por una parte la constitución de un nuevo vínculo societario de Felipe - que se denominó Posse Goytía y Cía. - y por otra parte, el comienzo de su participación en el mercado inmobiliario de la ciudad por $\$ 500 .{ }^{28}$ A partir de esta compra, la compañía no efectuó ninguna transacción comercial en el resto de la década.

En 1878, Felipe Posse falleció asumiendo la dirección de la empresa Felipe (hijo). Se incorporó a la misma, Rafaela Posse de Posse y Alejandro Posse. ${ }^{29}$ A partir de esta nueva organización, Rafaela poseía el $63 \%$ (\$ 87.282), Felipe Posse el 24\% (\$33.265) y Alejandro Posse el $13 \%$ (\$18.265).

Manuel Posse presenta un panorama diferente. En los predios de la fábrica añilera fundó el ingenio San Vicente. Esto marcó la continuidad de la sociedad con su hermano Wenceslao Posse y la incorporación de los hijos de ambos - Dermidio y Ataliva. Este emprendimiento culminó en 1873, transformándose Manuel Posse en el único propietario del San Vicente. ${ }^{30}$

En 1875 constituyó una sociedad con su hermano Emidio Posse y Agustín Muñoz Salvigni - uno de los principales prestamistas de la ciudad junto a Felipe Posse - que adquirió la fabrica azucarera "los Aguirre" perteneciente a José Justo de Urquiza y Baltasar Aguirre. ${ }^{31}$ La adquisición total de las acciones de este ingenio significó una erogación total de $\$ 8000$. La viuda de Urquiza mantenía una deuda con Posse por el mismo capital, por lo que este último se transformó en el principal accionista de esta compañía.

${ }^{26}$ AHT, Sección Protocolos, Serie C, 1872, f. 164 (v); Serie D, f. 2, f. 102 (v); 1873, f. 56 , f. 393 (v); 1874, f. 69 (v); 1876, f. 45, f. 435; 1878, f. 20, f. 213 (v), f. 432, f. 683 (v).

${ }^{27}$ AHT, Sección Protocolos, Serie D, 1871, f. 190 (v); 1873, f. 369 (v); 1875, f. 109; Serie A, 1877, f. 134; Serie D, 1878, f. 217.

${ }^{28}$ AHT, Sección Protocolos, Serie C, 1877, f. 280 (v).

${ }^{29}$ El testamento data de 1875 pero no se hizo efectivo hasta 1879 , año en que falleció Felipe Posse. Asimismo, Felipe (hijo) continuó como el administrador del ingenio. AHT, Sección Protocolos, Serie A, 1875, f. 346.

${ }^{30}$ En el proceso de disolución Wenceslao le cedió el paquete accionario a su hermano Manuel. Este último le quedó debiendo a Dermidio 995.65 pesos a pagar en cinco anualidades y le queda adeudando 75.000 pesos a Wenceslao a pagar en cinco anualidades de 15.000 pesos. AHT, Sección Protocolos, Serie A 1873, f. 311; Serie D, 1875, f. 326.

${ }^{31}$ AHT, Sección Protocolos, Serie D, f. 326. 
Sin embargo, en el transcurso del proceso de modernización azucarera esta empresa no pudo afrontar la tecnificación del ingenio por lo que cerró a principios de la década de 1880 .

Una cuestión que subyace es un marcado interés en la adquisición de propiedades en la campaña tucumana aunque las mismas no se destinaron a aumentar la superficie cultivada del ingenio San Vicente como ocurrió con Felipe Posse. Por un lado, Manuel Posse compró dos estancias en la zona de Lules por $\$ 1240 . .^{32}$ Las propiedades se situaban en los linderos del ingenio la Reducción que pertenecía a la sociedad que estableció su padre Vicente con sus hijos Emidio y Ramón. ${ }^{33}$ De esta manera, conservó propiedades que se utilizaron posteriormente en la expansión de la superficie cultivada de la Reducción evitando su adquisión por particulares ajenos al entorno familiar. Por otro lado, adquirió unas estancias en los departamentos de Trancas y Burruyacú por un valor de $\$ 4436$ para la cría de ganado vacuno y caballar. ${ }^{34}$ La actividad ganadera se transformó junto con la azucarera en los ejes de inversión del capital de Manuel Posse. ${ }^{35}$

Existen diferencias entre ambos casos. La presencia de Felipe y de Manuel Posse en el negocio azucarero es totalmente dispar debido a tres motivos: 1) el momento de la fundación de los ingenios San Felipe y San Vicente - el primero en 1865 y el segundo en 1872 - lo que incidió en la situación de ambas fábricas. La primera de ellas tiene una estructura interna organizada mientras que la segunda recién se instalaba en el medio local. 2) La constitución de una empresa familiar - Felipe Posse y Cía. - reflejó una cierta especialización y la división de roles en el contexto administrativo, hecho que resultó beneficioso. Felipe se encargó de la adquisición de propiedades para el ingenio y su hijo de administrar la fábrica azucarera. Asimismo, a partir del fallecimiento de Felipe Posse, se incorporaron a la compañía su viuda - Rafaela Posse de Posse - y Alejandro Posse aunque quien administró el ingenio fue Felipe Posse (hijo). En el caso de Manuel, su hijo se retiró del emprendimiento azucarero, quedando él sólo como administra-

${ }^{32}$ AHT, Sección Protocolos, Serie A, 1872, f. 337, f. 392.

${ }^{33}$ Esta sociedad se constituyó en 1859 y estos fueron los ítems. Vicente aportó un capital 26.804 pesos, Emidio 2500 y Ramón 7531 . Se gastan 1865 pesos en concepto de elementos necesarios. Se le debe entregar a Vicente la cantidad de 1600 pesos durante 10 años por gastos particulares, por haber aportado mayor capital. AHT, Sección Protocolos, Serie A, 1859, f. 204 (v).

${ }^{34}$ AHT, Sección Protocolos, Serie A, 1872, f. 212; 1876, f. 105; 1877, f. 45; 1878, f. 52 (v), f. 244 .

35 "Esta estancia (con sus 7000 cabezas de ganado) es una de las tres más importantes de la provincia junto con 'Alto de las salinas' de Wenceslao Posse y 'La Ramada' de Rufino Cossio”. En: Arsenio Granillo, Memoria histórica y descriptiva de la provincia de Tucumán (Buenos Aires 1882), p. 507. 
dor. 3) La producción azucarera se transformó en la actividad central de Felipe Posse, mientras que Manuel se orientó hacia a la explotación ganadera transformándose la agroindustria azucarera como una actividad complementaria.

En el mercado inmobiliario tucumano, las adquisiciones de Felipe Posse favorecieron la ampliación de la superficie cultivada del ingenio, aunque la compra de propiedades en la ciudad se presentó como un rubro significativo. Los inmuebles adquiridos en la ciudad fueron destinados a cuartos de alquiler hecho que generó la percepción de una renta que aumento el capital patrimonial de Posse.

La tendencia de Posse a invertir en el crecimiento del ingenio azucarero coincide con una coyuntura favorable que atravesaba la agroindustria local por tres motivos: 1) La exposición industrial realizada en la ciudad de Córdoba en 1871 ofreció la oportunidad a los empresarios tucumanos para demostrar el crecimiento de esta producción, lo que dejo satisfechos a los representantes nacionales. 2) La creación del banco San Juan generó expectativa debido a que uno de los propósitos de esta entidad era paliar la falta de dinero metálico nacional. ${ }^{36}$ Este banco cumplió otra función primordial en el contexto local, al transformarse en la instituición crediticia que facilitó a los industriales modernizar sus ingenios en la década de 1880.3) El proyecto presentado por el Estado Nacional para extender la línea ferroviaria desde la ciudad de Córdoba a Tucumán generó confianza en los empresarios tucumanos con respecto a la futura rentabilidad del negocio azucarero. ${ }^{37}$

El caso de Manuel Posse fue diferente debido a la heterogeneidad de sus intereses al combinar la compra de propiedades para el negocio azucarero como para la explotación ganadera. En cuanto al mercado inmobiliario de la ciudad Posse no tuvo presencia efectiva en el transcurso de la década de 1870 .

La constitución de vínculos societarios se presentó como una constante en ambos casos. Sin embargo, la utilidad que cada uno le asignó fue diferente. Con respecto a Felipe Posse, la constitución de sociedades representó una alternativa eficaz en la década de 1860 debido a que el capital inicial que arriesgó junto a Roque Pondal no fue significativo, hecho que no incidiría en su patrimonio en caso de fracasar el emprendimiento económico. En este mismo período, fundó Felipe Posse y Cía. mediante la cual canalizó todas las inversiones inmobiliarias en la zona de la campaña, atendiendo de

${ }^{36}$ Esta situación, afectaba la economía de la provincia en la que circulaban diferentes monedas, principalmente el peso boliviano. En: Guy, Política azucarera (nota 3), p. 60.

${ }^{37}$ La extensión del ramal ferroviario desde Córdoba hasta Tucumán se realizó en 1876, brindándole a los industriales la posibilidad de modernizar sus ingenios. 
manera particular las adquisiciones de propiedades en la ciudad. En la década siguiente, la compañía perdió presencia efectiva en el mercado inmobiliario y Felipe asumió en su persona la adquisición de propiedades, lo que indicó un cierto grado de especialización en la administración empresaria y una situación económica favorable debido al aumento sustancial de operaciones inmobiliarias en la década de 1870. Asimismo, la constitución de una compañía familiar está indicando un grado de cohesión significativo entre el padre y el hijo que se muestran interesados en la misma actividad.

Manuel Posse no presentó estas características. Los vínculos societarios fueron un medio para invertir en el negocio azucarero sin arriesgar un capital excesivo debido a que la posición económica de Manuel en contraposición con Felipe era menos favorable. Por este motivo, intentó en dos oportunidades involucrarse en el negocio azucarero pero sólo consiguió fundar el ingenio San Vicente.

Asimismo, las prácticas económicas implementadas por los casos analizados estaban relacionadas con las estrategias políticas del clan Posse en el período estudiado, temática a tratar en el siguiente apartado.

\section{Construcción, consolidación y culminación del poder político del clan Posse en Tucumán. Algunas consideraciones al respecto entre 1852-1880}

La consolidación del patrimonio económico de Felipe y Manuel Posse estuvó acompañado por un creciente interés en la vida política de Tucumán. Este clan familiar intentó consolidar un espacio de poder en la elite local, hecho que los motivó a participar en las sublevaciones con el régimen rosista.

Derrotado Rosas, Urquiza invitó a los gobernadores a San Nicolás de los Arroyos para convocar un congreso que dictase una constitución. Celedonio Gutiérrez, quien hasta ese momento permanecía como gobernador representó a Tucumán. Su ausencia brindó a sus opositores la oportunidad de hacer uso de ciertos artilugios legales para destituirlo. El diputado Zavalía presentó un proyecto de ley que duplicaba la representación en la Sala de Representantes de los diputados de algunos departamentos. Luego de la aprobación de esta ley, la oposición consiguió la mayoría en la Sala y destituyó a Gutiérrez. ${ }^{38}$ El gobernador depuesto organizó una fuerza militar desde Santiago del Estero e invadió Tucumán. Sin embargo, fue derrotado

${ }^{38}$ Uno de los instigadores de esta reforma fue José Posse con la ayuda de sus primos Manuel Posse (departamento Capital) y Luis Posse (departamento Monteros). En: Actas de la Sala de Representantes, tomo II (desde 1823 hasta 1852) (Tucumán 1939), pp. 31, 291 y 295. 
por José María del Campo, quién luego sería elegido por la Sala de Representantes como mandatario. ${ }^{39}$

La gobernación de Del Campo consolidó a los Posse en el ámbito local. Esta familia apoyó económicamente a las tropas que el cura dirigió para enfrentar a Gutiérrez. Cuando en 1854, Del Campo asumió la gobernación, de acuerdo con Páez de la Torre, "lo apoyaba la poderosa familia de los Posse que era a la sazón, el partido del gobierno" ${ }^{40}$. De esta manera, se transformó en el principal aliado de este clan familiar que poco después utilizó sus recursos - clientela, influencia política, red de vínculos personales - para convertirse en el sector hegemónico del ámbito tucumano. De acuerdo con Gutiérrez, la red familiar de los Posse se encontraba cohesionada por diversas empresas económicas, destacándose las actividades comerciales, los ingenios y las plantaciones. ${ }^{41}$

La alianza entre Del Campo y el clan familiar se concretó con el nombramiento de José Posse como Ministro General de Gobierno aunque su designación fue resistida por el sector liberal que apoyaba al gobernador. ${ }^{42}$ Ante el avance de la política de fusión por parte de un sector del partido liberal, Del Campo reafirmó su influencia con el apoyo de los Posse..$^{43} \mathrm{La}$ familia ocupó cargos en la Sala de Representantes de la legislatura entre 1852 y 1861. Entre ellos se identificó a Emidio Posse como presidente de la Comisión de Contribución Territorial y Mobiliaria del departamento Chicligasta, y Manuel Posse con el mismo cargo en Famailla. ${ }^{44}$

Cuando finalizaba el mandato de Del Campo, dos candidatos luchaban por la gobernación. Esto suscitó la descomposición del partido liberal en dos facciones que midieron la fortaleza de sus alianzas y vínculaciones políticas en la elección a gobernador. Una de ellas apoyó a Anselmo Rojo quien propugnó una política de fusión con el gobierno Nacional y la otra a

${ }^{39}$ Ibidem, p. 348

${ }^{40}$ Carlos Páez de la Torre, Historia de Tucumán (Buenos Aires 1986), p. 519.

${ }^{41}$ Florencia Gutiérrez, Las prácticas políticas en Tucumán en la década de 1860. El partido Posse (Tucumán 1997), p. 5.

${ }^{42} \mathrm{El}$ gobernador procuró fortalecer su posición nombrando nuevamente a Posse como ministro general, cargo de claras connotaciones políticas, puesto que en esa cartera se decidía el armado de las candidaturas de diputados. En: María Celia Bravo, "La política 'armada' en el norte argentino. El proceso de renovación de la elite política tucumana, (1852-1862)": Hilda Sabato/Alberto Lettieri (eds.), La vida política en la Argentina del siglo XIX. Armas, votos y voces (Buenos Aires 2003), pp. 243-258, aquí: p. 250.

43 La política de fusión intentó la unificación de los intereses políticos tucumanos con el proyecto de construcción del Estado Nacional.

44 Esto implicaba que eran diputados por esos departamentos, en: Ramón Cordeiro/Carlos Dalmiro Viale, Compilación ordenada de leyes, decretos y mensajes del periodo constitucional que comienza en el año 1852, Vol. II (1857-61) (Tucumán 1815), pp. 324 y 467. 
José Posse, que estaba en contra de la autoridad de Urquiza ${ }^{45}$ El día del sufragio, un grupo de adeptos de la familia Posse presionó a la Sala de Representantes para que eligiera a José como gobernador. Luego de ser desalojados del recinto la elección se volcó a favor de Rojo. El clan Posse no aceptó el resultado de la votación y conspiró junto con el ex-gobernador Del Campo para destituir a Rojo.

La primera disposición de Rojo fue el desmantelamiento de las bases de poder de los Posse quienes significaban una amenaza política latente:

\begin{abstract}
"su primera acción efectiva se dirigió hacía el comandante de Monteros, Benjamín Posse, a quien quitó inmediatamente su investidura. Todo parecía indicar que las próximas víctimas serían José Ciriaco y Ramón Posse, hombres fuertes en la Reducción y en Lules, respectivamente [...] No es casual que los primeros objetivos tendientes a terminar con el poderío de los Posse hayan sido encauzados hacía los comandantes de las zonas aledañas", ${ }^{46}$
\end{abstract}

Los Posse, ante la restricción de su predominio político organizaron un levantamiento armado que fue denominado como la Revolución de los Posse. ${ }^{47}$

El acceso a la cima del poder político de este clan familiar se concretó luego de 1861, en concordancia con el triunfo de Mitre frente a Urquiza en la batalla de Pavón. Esta victoria permitió a los sectores dominantes porteños "nacionalizar" la llamada revolución liberal y organizar el Estado. ${ }^{48}$

Durante el transcurso de esos acontecimientos, en Tucumán se vivía un enfrentamiento entre las fuerzas liberales - dirigidas por el cura Del Campo -, quien nuevamente aparece en escena y las federales, lideradas por Navarro, que intentaban depurar la provincia de la influencia liberal. El triunfo de Mitre inclinó la balanza a favor de las fuerzas liberales que con el apoyo del clan santiagueño de los Taboada reubicaron a Tucumán dentro de la esfera liberal.

Unos meses después, Del Campo derrotó a la montonera federal dirigida por Chacho Peñaloza y Celedonio Gutiérrez. ${ }^{49}$ Este triunfo posibilitó al ex presbítero acceder a la gobernación. De este modo, los Posse retornaron al escenario político local. La identificación de esta familia con el Partido

${ }^{45}$ Gutiérrez, Las prácticas políticas (nota 41), p. 8.

${ }^{46}$ Ibidem.

47 "El fracaso de esta aventura revolucionaria determinó el destierro de Del Campo y de varios miembros de la familia Posse, al tiempo que los partidarios de la política de fusión operaban como el círculo del nuevo gobernador." En: Bravo, "La política 'armada" (nota 42), p. 253.

${ }^{48}$ Oscar Oslak, La formación del Estado Argentino. Orden, progreso y organización nacional (Buenos Aires 1997), p. 44.

${ }^{49}$ Páez de la Torre, Historia de Tucumán (nota 40), p. 529. 
Nacionalista de Mitre y los posteriores lazos de amistad que establecieron con el Presidente consolidó a este clan en el ámbito local y regional.

Del Campo nombró como su ministro general a Arsenio Granillo esposo de Sabina Posse Talavera - y eligió como diputado nacional a José Posse.$^{50}$ Nuevamente, en 1864, se convocó a elecciones para gobernador y no fue extraño que este último fuese elegido por amplia mayoría como nuevo Jefe de la Ejecutivo. ${ }^{51}$ De esta manera, Mitre consolidó la postura liberal en el norte argentino. Por un lado, contaba con gobiernos que se situaban en la misma sintonía que el Estado Nacional y por otro lado, la lealtad de los Taboada - en Santiago del Estero - que se transformaron en el brazo armado de Mitre en el norte del país. ${ }^{52}$

Una característica del gobierno de José Posse y posteriormente de su primo Wenceslao, fue la injerencia familiar en puestos claves del gobierno, especialmente los cargos que ocuparon en el Colegio Electoral en el decenio de 1860. El sistema eleccionario era por sufragio indirecto. Los ciudadanos elegían a los electores por cada departamento de la provincia y este cuerpo era el encargado de nombrar al gobernador. En la década de 1860 fueron electores los siguientes integrantes de la familia: Manuel Posse (1860-64), Emidio Posse (1865), Juan Posse (1866), Roque Pondal Posse (1862-65), Tiburcio Molina (1863-65-67). ${ }^{53}$ En el contexto nacional desempeñaron funciones como senador - Manuel Posse en 1866 -, y como diputado - Filemón Posse en 1864. ${ }^{54}$ Estos cargos beneficiaron al clan que se relacionó con los representantes de otras elites provinciales y de Buenos Aires constituyendo nuevos vínculos de amistad y reciprocidad política que resultaron favorables en coyunturas políticas adversas.

Al concluir José su mandato, Wenceslao Posse - primo del saliente mandatario - fue elegido Gobernador de Tucumán. ${ }^{55} \mathrm{Al}$ iniciar su gestión nombró como ministro general a Del Campo, lo que marcó la persistencia de la alianza política con el cura. La familia continuó monopolizando

${ }^{50}$ Sabina era hija de Vicente Posse, hermana de Manuel y sobrina de Felipe.

${ }^{51}$ Ramon Cordeiro/Carlos Dalmiro Viale, Compilación ordenada de leyes, decretos y mensajes del período constitucional que comienza en el año 1852, Vol. III (1862-1867) (Tucumán 1915), p. 175.

${ }^{52}$ Miguel Taboada fue designado jefe de la frontera del Chaco y de la Circunscripción Militar del Norte, en: Gutiérrez, Prácticas políticas (nota 41), p. 15.

${ }_{53}$ Cordeiro/Viale, Compilación ordenada (nota 51), p. 178.

${ }^{54}$ Diario de Sesiones de la Cámara de Diputados del Congreso de la Nación, 1864, (Buenos Aires, 1865), p. 3. Diario de Sesiones de la Cámara de Diputados del Congreso de la Nación, 1866 (Buenos Aires 1867), p. 5.

${ }^{55}$ Cordeiro/Viale, Compilación ordenada (nota 51), p. 341. 
los puestos claves en la administración pública y en la legislatura de la provincial. $^{56}$

En 1866, Wenceslao accedio a la gobernación y la familia contaba con una alta participación en el ámbito político. Arsenio Granillo era diputado por Monteros; Benigno Vallejo, Silvestre del Campo y Manuel Posse por la Capital; Roque Pondal Posse por Lules; Arcadio Talavera por Graneros y Emidio Posse por Famailla. ${ }^{57}$ Sin embargo, la manipulación de los espacios de poder por parte de la familia Posse generó la división del partido liberal en dos facciones que representaron no sólo las candidaturas presidenciales sino los dos grupos antagónicos. Por un lado se situaba el grupo posista (Club Sarmiento) que apoyaba a Sarmiento, y por otro lado, el denominado Club del Pueblo que sostenía la candidatura de Rufino Elizalde (aspirante de Mitre) y apoyado por los Taboada de Santiago del Estero.

Con el sustento del clan santiagueño y liderado por Octaviano Luna, los integrantes del Club del Pueblo, derrocaron a Wenceslao Posse del gobierno. Ante las circunstancias desventajosas que se le presentaron no tuvo otra opción que renunciar ante la Sala de Representantes. El único integrante de la familia que reaccionó ante este hecho fue Emidio Posse. ${ }^{58}$

La permanencia en el poder de los Posse fue una de las causas del movimiento revolucionario. Un sector de la elite no apoyaba el manejo exclusivo de la política por parte de los Posse por lo que no dudaron en apoyar a los revolucionarios.La oposición se organizó en el Club del Pueblo, confirmación no sólo de una candidatura presidencial sino de la oposición en contra de este clan.

La asunción de Luna como gobernador determinó la renuncia de los adeptos al partido posista. El mandatario persiguió a esta familia con diferentes medidas entre los que se destacaron los empréstitos forzosos contra las compañías de Felipe Posse. ${ }^{59}$ La actitud de Luna desencadenó la reorganización de la familia que intentó recuperar el poder y desalojar a los mitristas del gobierno.

56 "La legislatura provincial durante el gobierno de los Posse fue el reducto de amigos y parientes, pero contrariamente a lo que se podría llegar a pensar, este hecho no modificó en lo sustancial las repetidas inasistencias de los diputados." En: Gutiérrez, Prácticas políticas (nota 41), pp. 26-27.

${ }^{57}$ Cordeiro/Viale, Compilación ordenada (nota 51), p. 369.

${ }^{58}$ De acuerdo con la tradición familiar, se movilizó rápidamente para organizar la contraofensiva con las tropas de su comandancia. Con una importante fuerza puso sitio a la ciudad pero por pedido expreso de su hermano prisionero - Wenceslao -, optó por desarmar la partida cuando se disponía a ingresar en la plaza principal. José María Posse, Los Posse. El espiritu de un clan (Buenos Aires 1997), p. 106.

${ }_{59}$ AHT, Sección Mayores de Contaduría, 1868, f. 7. 
No obstante, las tentativas de los mitristas por mantenerse en el poder fracasaron ante la eleccion de Sarmiento como presidente de la Nación. Esto desarticuló las ambiciones de Luna y los Taboada en el contexto regional. El nuevo mandatario estaba en contra de la influencia de la familia santiagueña en el Noroeste, motivo por el que fraguó un plan para despojarlos del poder que ejercían en la región. Además, la existencia de un grupo de marcada tendencia mitrista, con un apreciable contingente militar, no inspiraba tranquilidad al Estado Nacional. Sin embargo, el triunfo de Sarmiento no significó el retorno de la familia Posse al poder. De acuerdo con Herrera esto ocurrió por dos motivos: 1) El prestigio político de este clan era cuestionado por una parte de la elite tucumana lo que provocaba conflicto en el ambiente local. 2) Ante esta situación, Sarmiento nombró a Usladislao Frías como su Ministro del Interior en vez de a su amigo José Posse. De esta manera evitó cuestionamientos del sector político tucumano y divisiones facciosas. ${ }^{60}$

El manejo exclusivo del poder por parte de los Posse en la década de 1860 - entre 1863 y 1867 - suscitó un rechazo de la elite tucumana a futuras candidaturas de sus miembros, lo que generó un obligado ostracismo político en el contexto local. Esta situación marcó la reorientación del clan familiar hacia diversas actividades como la azucarera. En el caso específico de Felipe y Manuel Posse, la década de 1870 significó un período de expansión de sus inversiones y la implementación de una serie de prácticas empresarias que consolidaron su situación en el medio local, más allá de las vicisitudes de la política local y nacional. En este sentido, el decenio de 1880 fue un período coyuntural específico que puso a prueba los logros empresarios y económicos previamente conseguidos.

\section{Proceso de modernización azucarera, nuevas contiendas políticas de los Posse y cierre de los ingenios San Felipe y San Vicente}

En las páginas precedentes se realizó un recorrido por las estrategias económicas, las prácticas empresarias y las vicisitudes políticas que atravesó el clan Posse entre 1852 y 1880. Esta reconstrucción del proceso vislumbró el panorama que se le presentó a esta familia en el contexto local en la década de 1880 .

${ }^{60}$ Claudia Herrera, Elites y poder en Argentina y España en la segunda mitad del siglo XIX (Madrid 2003), p. 127. 
Al poco tiempo del tendido de las vías férreas entre Córdoba y Tucumán, un grupo de empresarios azucareros - entre los que se encontraban los hermanos Méndez y Wenceslao Posse - invirtieron en nuevas maquinarias para sus ingenios. ${ }^{61}$

Esta tecnificación se llevó a cabo con la asistencia del gobierno nacional. Una de las medidas que benefició a los industriales fue la reducción del flete de transporte que permitió la importación de maquinaria desde Inglaterra y Francia. Del mismo modo, el Banco Nacional se transformó en el nuevo ente crediticio en menoscabo del banco San Juan - máximo organismo financiero de fines de la década de 1870 - en el contexto tucumano. La nueva entidad bancaria utilizaba moneda nacional, mientras que el San Juan operaba con pesos bolivianos. Sin duda, ésta no fue la única causa que ocasionó el cierre de este banco, también incidió la agresiva política de bajas tasas de interés que ofreció la entidad nacional, lo que derivó en la liquidación del San Juan. Asimismo, el Estado Nacional implementó una legislación proteccionista que favoreció a la producción tucumana frente a los azucares fabricados en otras partes de América Latina y Europa ${ }^{62}$

Este contexto favorable tenía una estrecha vinculación con la elección del tucumano Julio A. Roca como presidente de la Nación en 1880. El compromiso del mandatario con sus comprovincianos tenía relación con el apoyo brindado por el electorado tucumano en la contienda presidencial y los vínculos personales establecidos desde su juventud con diversas familias - los Nougués, los Padilla, los Terán, los Etchecopar - quienes eran industriales azucareros. ${ }^{63}$ Sin embargo, el proceso de modernización generó una contracción en el número de ingenios en Tucumán. De 52 ingenios a principios de 1860, sólo quedaron una treintena; debido a que no todos los propietarios pudieron modernizar sus fábricas. ${ }^{64}$ Estos empresarios quedaron marginados del proceso de fabricación, monopolio exclusivo de aquellos industriales que atravesaron con éxito el proceso de modernización debido a los contactos económicos y los vínculos personales que poseían.

${ }^{61}$ Wenceslao en la década de 1860 fue el pionero en instalar una maquina clarificadora en el Esperanza.

${ }^{62}$ La legislación proteccionista de esta agroindustria se remontaba al gobierno de Alejandro Heredia que fue uno de sus precursores en el contexto provincial.

63 "La burguesía tucumana apelo exclusivamente a conexiones personales [...] Diputados y senadores nacionales eran, naturalmente, embajadores de estos intereses en Buenos Aires, combinando fácilmente un papel oficial con la búsqueda de favores concretos para familiares y amigos". En: Balán, "Una cuestión regional" (nota 3), p. 72.

${ }^{64}$ Páez de la Torre, Historia de Tucumán (nota 40), p. 557. 
El control de la empresa Felipe Posse y Cía. fue asumido por Felipe (hijo), quien administró este emprendimiento en nombre de la familia. Por este motivo, con el propósito de aumentar la superficie cultivada del ingenio en 1881 y 1882 adquirió propiedades en los Aguirre por $\$ 2060{ }^{65}$

En 1882, al igual que otros empresarios del azúcar, modernizó el ingenio con la compra de 7 motores a vapor y uno hidráulico que transformaron al San Felipe en una fábrica de medianas dimensiones por el volumen de su producción en el contexto local. El capital invertido para esta reconversión tecnológica no era genuino debido a que la empresa familiar carecía de los recursos necesarios para ello. Ante esta eventualidad recurrió al crédito público solicitando un préstamo al Banco Nacional a devolver en diez años. ${ }^{66}$

Ese mismo año, los herederos de Posse finalizaron las operaciones económicas de Felipe Posse y Cía. en Tucumán constituyéndose en su remplazo Posse Hnos. y Cía. ${ }^{67}$ De este emprendimiento participaron la viuda Rafaela Posse de Posse - y sus hijos - Felipe y Alejandro -, quienes por cláusula establecida en el nuevo contrato de asociación se hicieron cargo de la deuda pasiva del ingenio San Felipe y de la sociedad Posse Goytía y Cía. Asimismo, al no encontrarse inventariados el valor de las maquinarias adquiridas por la anterior administración, la nueva sociedad se comprometió al pago de las mismas, como así también de cualquier otra deuda que existiese a favor del Banco Naciónal. ${ }^{68}$

En 1883, Posse Hnos. y Cía. adquirió propiedades en la capital tucumana. Se invirtió \$ 16.560 en cuatro sitios en los alrededores de la plaza central, lugar en donde la cotización de los inmuebles era superior por su ubicación. ${ }^{69}$ La compra de maquinaria para el ingenio y propiedades en la campaña y la ciudad revelaron la continuidad de la expansión de la empresa familiar. Esta afirmación se sostiene en la conducta de esta compañía que sólo recurrió al endeudamiento como una alternativa para optimizar la producción del ingenio. La utilización del crédito estatal se planteó como una alternativa frente a un medio sumamente competitivo. Asimismo, el pago mensual del crédito solicitado no generó un recorte presupuestario en la empresa, que continuó sus actividades económicas tendientes a la acumulación de capitales y mejora del patrimonio de Posse Hnos. y Cía.

${ }^{65}$ AHT, Sección Protocolos, Serie D, 1881, f. 137, f. 139; 1882, f. 121 y f. 123.

${ }_{66}^{6}$ Posse, Los Posse (nota 58), p. 108.

${ }^{67}$ AHT, Sección Protocolos, Serie D, 1882, f. 357 (v).

${ }^{68}$ El resto de los integrantes de la familia Posse-Posse cobraron el paquete accionario que les correspondía del activo del ingenio.

${ }^{69}$ AHT, Sección Protocolos, Serie D, 1883, f. 825 (v), f. 1165, f. 1387, f. 1421. 
En 1882 Manuel Posse reemplazó los primitivos trapiches de su ingenio por maquinaria moderna. Sin embargo, carecía del capital genuino para realizar dicha inversión motivo por el cual recurrió al crédito nacional.

En este panorama económico alentador, los Posse intentaron recuperar el prestigio político. ${ }^{70} \mathrm{La}$ oportunidad se presentó en la elección de candidaturas para diputado nacional. José Posse manifestó su interés para ocupar este cargo y presionó al gobernador Nougués, esgrimiendo su parentesco con el presidente Roca. Pese a la presión ejercida por "Pepe" Posse, el gobernador no cedió ante esta propuesta. ${ }^{71}$ Esta contienda política no fue totalmente perdida por el clan familiar que consiguió que Emidio Posse primo de José - fuera elegido diputado nacional en $1882 .{ }^{72}$

A partir de 1884, la política local atravesó un período de tensión significativo, producto de la elección de Santiago Gallo como gobernador, quien derrotó al candidato roquista. Sin embargo, la designación de Gallo no era la cuestión de fondo, sino el apoyo que manifestaron el gobernador y número importante de electores tucumanos a la candidatura presidencial de Bernardo de Yrigoyen en contraposición al candidato del Partido Autonomista Nacional (PAN), Juárez Celmán. Esta situación provocó la reacción de los sectores juaristas quienes solicitarion la Intervención Federal a la provincia. El Estado Nacional desatendió estos pedidos debido a que el presidente respeto la decisión del electorado tucumano. No obstante, Roca reconoció que sería insostenible el gobierno de Gallo si resultaba electo Juárez Celman. Por este motivo, se reunió con el mandatario tucumano y le propuso una solución. Si la fórmula Celman-Pellegrini obtenía la victoria, Gallo renunciaría y el Colegio Electoral nombraría a una persona "potable" para el ejecutivo. Esta responsabilidad recayó en Juan Posse, primo de Roca. ${ }^{73}$

${ }^{70} \mathrm{El}$ aliciente principal para los Posse era el hecho de ser los únicos parientes que el presidente Roca tenía en Tucumán.

71 "La lealtad del gobernador Nougués hacia Roca impidió que se realizara un contrato bancario, pero se negó a aceptar órdenes que pusieran en peligro las alianzas locales. Lo que más podía irritar al electorado era que la familia Posse volviera a la escena política.” En: Guy, Política azucarera (nota 3), p. 49.

${ }^{72}$ Diario de Sesiones de la Cámara de Diputados del Congreso de la Nación, 1882, Buenos Aires, p. 5.

${ }^{73}$ De acuerdo a la tradición familiar el gran artífice de la designación y de la confianza que Roca depositó en su primo fue Emidio Posse que años antes fue elegido diputado nacional. Este último aprovecho la cercanía con Roca - al residir en Buenos Aires gran parte del año por sus responsabilidades legislativas - y convenció a su primo de esta decisión. En: Posse, Los Posse (nota 58), p. 94. 
Juan Posse concilió con los juaristas con el propósito de solucionar los conflictos políticos en Tucumán. Con este fin encomendó al diputado nacional Delfín Gallo, que se reuniera con los juaristas para hallar una solución. Sin embargo, las negociaciones fracasaron debido a que el sector juarista le solicitó a Posse, dos ministerios, la mitad de la legislatura (obligando a renunciar a los diputados ya electos), la mitad del Colegio Electoral y la jefatura de la policía. ${ }^{74}$ Estas demandas fueron rechazadas, lo que aumentó la conflictividad con el gobierno. Los juaristas, ante este fracaso, se valieron de todos los recursos a su disposición - con la complicidad de Juárez Celmán - mediante la utilización de los funcionarios públicos que dependían del Estado Nacional, entre ellos los del Banco Nacional, del Banco Hipotecario, de la Gerencia del Ferrocarril del Norte y de la Administración de Correos.

En el sector financiero, el Banco Nacional apremió a todos los opositores al juarismo - especialmente a los industriales azucareros -, a pagar los créditos otorgados para la modernización de sus ingenios. ${ }^{75}$

En 1887, Lídoro Quinteros reunió una fuerza militar en Córdoba y se dirigió hacía Tucumán utilizando el ramal ferroviario Central Córdoba. Una vez en la provincia organizó un movimiento revolucionario apoyado por los industriales fieles al PAN - entre ellos Nougués, Padilla, Hileret -, quienes organizaron las peonadas de sus ingenios para derrocar a Juan Posse del poder. La provincia fue intervenida por el Estado Nacional por el término de unos meses hasta la designación de Lídoro Quinterios como gobernador por parte de la legislatura local.

A partir de este momento, el juarismo ejerció presión sobre la oposición. En este sentido, el Banco Nacional solicitó la devolución de los préstamos efectuados a los industriales opositores al gobierno mientras que el sector azucarero juarista obtenía nuevos préstamos. Esto determinó el cierre de los ingenios San Vicente propiedad de Manuel Posse y el San Felipe perteneciente a Posse Hnos. y Cía. -, que en ese momento no poseían todo el capital para cancelar los préstamos. El triunfó del sector juarista marcó un nuevo fracaso para esta familia y la marginación empresaria del sector azucarero tucumano. ${ }^{76}$

${ }^{74}$ Diario de Sesiones del Congreso de la Nación, “intervención a Tucumán”, Buenos Aires, Edición Oficial, 1887, pp. 27-28.

${ }^{75}$ Guy, Política azucarera (nota 3), p. 70.

${ }^{76}$ El movimiento revolucionario mostró a un clan familiar políticamente disgregado debido a que algunos integrantes eran incondicionales al PAN, entre ellos, Benjamín Posse - nieto de José Víctor Posse - quien fue premiado por Juárez Celman con la banca de diputado por Tucumán. 


\section{Conclusiones}

Una característica en ambos casos fue la diversificación económica. No obstante, no sólo se analizó las actividades relacionadas con la agroindustria azucarera, sino también la compra de inmuebles y los préstamos a particulares. A los efectos de este trabajo se consideró que los rubros analizados fueron representativos para bosquejar el comportamiento económico de Felipe y Manuel Posse. Asimismo, no se desconoce que el origen del proceso de acumulación en los casos objeto de estudio comenzó con la instalación de sus primeros negocios - pulperías en la ciudad -, en donde comerciaban diversos artículos. En este sentido, la evolución económica de Felipe y Manuel Posse demostró que la acumulación previa de capitales no sólo provino de la actividad comercial y manufacturera de la elite sino también de otros intereses como las transacciones inmobiliarias y la constitución de sociedades como medio para incorporar capital.

Sin embargo, a pesar de que el proceso de acumulación comenzó con las actividades comerciales la evolución económica fue diferente para cada caso. Por un lado, Felipe Posse concentró su interés en la adquisición de inmuebles en la ciudad y en las cercanías del ingenio. Constituyó una sociedad con su hijo primogénito, hecho que le permitió desarrollar una serie de actividades alternativas que aumentaron su patrimonio. Por otro lado, el comportamiento económico de Manuel Posse no evidenció un propósito específico debido que alternó su interés en diversos emprendimientos, entre los que se destacaron la compañía añilera, sus inversiones en la agroindustria azucarera y las actividades agrícolas ganaderas.

En cuanto a las actividades políticas de Felipe y Manuel Posse existen ciertas particularidades. Entre 1830 y 1852, una característica de los Posse fueron los intentos de algunos de sus integrantes para desalojar del poder a los gobiernos "federales". En ninguna circunstancia estas iniciativas políticas tuvieron éxito. En este sentido, la rama familiar involucrada en estos sucesos fue la de los Posse Talavera - descendientes de Vicente Posse -, padre de Manuel. A partir de 1852, esta familia redefinió sus estrategias políticas. El éxito de las mismas estuvo supeditado al estrecho vínculo de amistad y lealtad que los unía con Del Campo, que se transformó en un aliado. Asimismo, se descubrió la existencia de una organizada estructura interna que asignó roles específicos a cada uno de los integrantes del clan. Los comandantes de campaña de los departamentos Monteros y Lules zona en donde ejercían influencia los Posse Talavera - utilizaban a la clientela que dependía de esta familia como una herramienta electoral en algunas ocasiones y como ejércitos particulares en otras. Los miembros de la familia y la red de parentesco que integraba la Sala de Representantes actuaron 
como un sector de oposición durante la década de 1850 en contra de la política de fusión propulsaba por Urquiza. En el decenio siguiente, durante el predominio de esta familia, se transformaron en el elemento legitimador de los proyectos presentados por el ejecutivo. Los diputados y senadores nacionales cumplieron la función de mantener abiertos los canales de comunicación con otras elites provinciales y con el gobierno nacional. Sin embargo, el liderazgo político fue ejercido por una persona que no pertenecía a la rama familiar de los Posse Talavera: José Posse Insúa. Este último fue el encargado de diseñar las estrategias del clan familiar y se transformó en el nexo de comunicación con Mitre y Sarmiento, quiénes apoyaron y eligieron a los Posse como los interlocutores de las necesidades del Estado Nacional en Tucumán.

En los casos específicos que se analizaron en esta investigación, la participación en el proceso de predominio político de la familia fue esencial. Tanto Felipe como Manuel Posse formaron parte de la Sala de Representantes, del Colegio Electoral y en algún momento desempeñaron funciones en el Congreso de la Nación. Sin embargo, a partir de la pérdida de prestigio político en la década de 1870 , se identificaron comportamientos disímiles. Por una parte, Felipe no participó nuevamente en esta clase de actividades y esto se debió principalmente a su avanzada edad. Por otra parte, Manuel regresó a la vida política cuando su primo - Julio A. Roca -, fue elegido presidente de la Nación.

Finalmente en el último período analizado, la realidad del clan era totalmente diferente. Los Posse, en la década de 1870, no recuperaron su prestigio debido a que la elite local objetaba su retorno al poder. Este rechazo nuevamente orientó el interés de los Posse Talavera hacía las actividades económicas, especialmente la agroindustria azucarera; debido a que la llegada del ferrocarril facilitó la modernización de los trapiches por modernas maquinas a vapor. La elección de Roca como presidente de la Nación se transformó en un nuevo aliciente político para los Posse debido a que eran los únicos parientes directos del nuevo mandatario. Sin embargo, esto no resultó así. Roca optó por mantener una política de consenso y no de imposición con las elites provinciales y especialmente con la tucumana que fue una de las artífices de su elección. En este sentido, toda esperanza de los Posse por obtener algún beneficio por su relación de parentesco fue en vano. La elite tucumana, con los Nougués a la cabeza, no permitió el regreso del clan familiar a los primeros planos.

Sin embargo, por un hecho fortuito en 1886 Juan Posse Talavera fue designado gobernador de Tucumán. Asimismo, esto no significó el regreso del clan familiar al poder. El mismo se hallaba totalmente disgregado, con integrantes que respondían a las filas del juarismo y otros que eran sus 
detractores. Esto desembocó en una revolución liderada por Lídoro Quinteros - con el apoyo de Juárez Celman -, que generó la persecución de todos los opositores al juarismo. Este hecho afectó de forma colateral a Felipe y a Manuel que por tener un grado de parentesco directo con el gobernador Juan Posse sufrieron el cierre de sus ingenios.

Los resultados obtenidos de los interrogantes planteados al comienzo de esta investigación fueron reveladores. En el decenio de 1880, el clan Posse se encuentra totalmente disgregado. Algunos de sus integrantes se sitúan en las filas del juarismo, mientras que otros apoyaron el mandato de Juan Posse. La revolución de 1887 marcó un punto de inflexión aún más fuerte porque amplió la brecha entre quienes se alinearon en las filas del juarismo y quienes fueron sus detractores. Sin embargo, ninguno de los dos casos analizados en este trabajo experimentó estos sucesos. Felipe Posse falleció en 1878 y su hijo administró el ingenio San Felipe, mientras que Manuel se retiró de la vida política por su avanzada edad. En este sentido, el cierre de los ingenios azucareros fue una represalia del sector juarista hacia el conjunto de industriales opositores a la política de Juárez Celman - entre los que se encontraban también familias como los Colombres y los Gallo -, pero que por ningún motivo se dirigió específicamente a los casos objeto de estudio. Continuando este eje de análisis, la disgregación del clan - vinculada a ambiciones políticas diferentes - afectó también los vínculos entre sus integrantes, que optaron por no reaccionar ante el cierre de los ingenios San Felipe y San Vicente.

En cierto sentido, el negocio azucarero, no fue una prioridad en los casos analizados, sino que formaba parte de las diferentes actividades que ambos desarrollaban. Un hecho significativo en el comportamiento económico de Felipe (hijo) y Manuel Posse fue el endeudamiento con el Estado Nacional - a través de los préstamos del Banco Nacional - para modernizar sus ingenios azucareros. En el caso de Felipe (hijo), esta estrategia respondió al hecho de que la empresa familiar no contaba con capital genuino para efectuar dicha inversión. En cuanto a Manuel, la situación era otra, debido a que contaba con los recursos necesarios para llevar a cabo la modernización de su ingenio, pero utilizó el crédito público con el propósito de no comprometer su patrimonio. Esta práctica fue implementada por gran parte de la elite azucarera que prefirió recurrir a las facilidades financieras que ofrecía el Estado Nacional. De esta manera, el margen de ganancias fue superior debido a que la inversión inicial no fue realizada por los industriales. Asimismo, refleja una conducta especulativa por parte de los industriales que no arriesgaba su patrimonio en caso de que el negocio azucarero resultase un fiasco.

Respecto del último de los interrogantes planteados, se considera que el cierre de los ingenios azucareros fue consecuencia de una complejidad de 
motivos: 1) Tanto Felipe (hijo) como Manuel Posse recurrieron al crédito estatal para modernizar sus fábricas azucareras y esta estrategia fue utilizada por la mayor parte de la elite tucumana. Sin embargo, un hecho político coyuntural, como fue la revolución que derrocó a Juan Posse afectó a todos los opositores al juarismo entre los que se encontraban los casos objeto de estudio. 2) En el período en que funcionaron los ingenios San Felipe y San Vicente, los réditos económicos fueron significativos. No obstante, en ninguno de los casos se optó por cancelar los créditos solicitados, optándose por utilizar las ganancias en el desarrollo de otras actividades. Por este motivo, al momento de que el Banco Nacional solicitó la devolución de los mismos, Felipe (hijo) y Manuel Posse carecían del capital para hacerlo. 3) Por ultimo, como se afirmó en un principio, la industria azucarera en los casos analizados formaba parte de un conjunto de actividades que estos individuos realizaban. Asimismo, el cierre de los ingenios no afectó de manera significativa a sus propietarios y las causas de este suceso se originaron a partir de una problemática vinculada con las alianzas políticas al interior de la elite tucumana, más que una mala administración de sus ingenios. 